\title{
Supplement to: A new approach to simulate aerosol effects on cirrus clouds in EMAC v2.54
}

Mattia Righi ${ }^{1}$, Johannes Hendricks ${ }^{1}$, Ulrike Lohmann ${ }^{2}$, Christof Gerhard Beer ${ }^{1}$, Valerian Hahn ${ }^{1}$, Bernd Heinold $^{3}$, Romy Heller ${ }^{1}$, Martina Krämer ${ }^{4}$, Christian Rolf ${ }^{4}$, Ina Tegen ${ }^{3}$, and Christiane Voigt ${ }^{1}$

${ }^{1}$ Deutsches Zentrum für Luft- und Raumfahrt (DLR), Institut für Physik der Atmosphäre, Oberpfaffenhofen, Germany

${ }^{2}$ Institute for Atmospheric and Climate Science, ETH Zürich, Zürich, Switzerland

${ }^{3}$ Leibniz Institute for Tropospheric Research (TROPOS), Leipzig, Germany

${ }^{4}$ Research Centre Jülich, Institute for Energy and Climate Research 7: Stratosphere (IEK-7), Jülich, Germany

Correspondence to: Mattia Righi (mattia.righi@dlr.de)

In this Supplement additional figures are shown, which complement the evaluation of EMAC-MADE3 presented in Sect. 4 of the paper. For details about each figure, see the corresponding sections in the paper as mentioned in the figure captions.

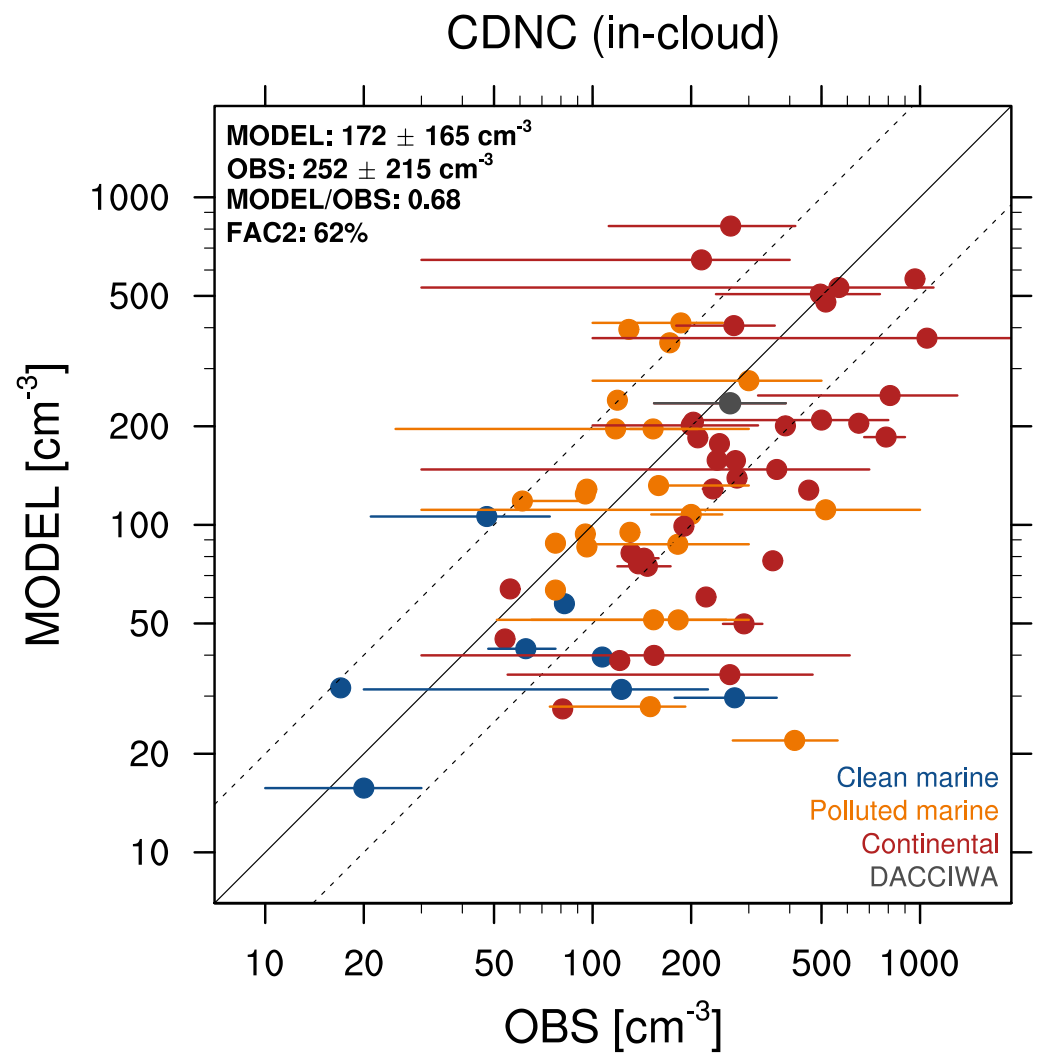

Figure S1. As in Fig. 3 in the paper, but using a different method for calculating supersaturation in liquid clouds. See Sect. 4.3 in the paper for details. 


\section{EMAC}

Cloud Droplet Number Concentration $\left[\mathrm{cm}^{-3}\right]$

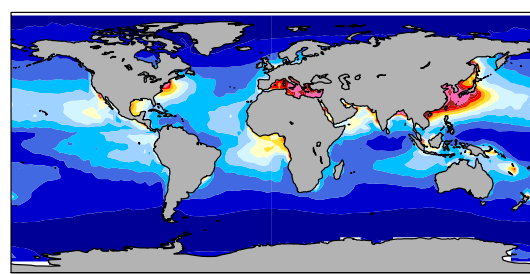

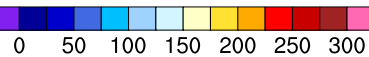

Bennartz17

Cloud Droplet Number Concentration $\left[\mathrm{cm}^{-3}\right]$

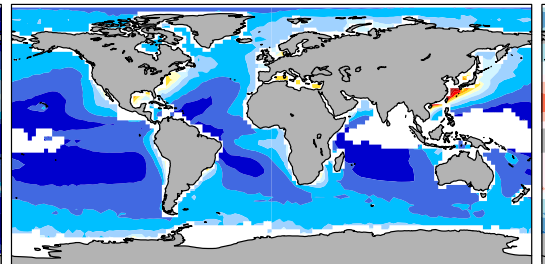

$\begin{array}{llllllll}0 & 50 & 100 & 150 & 200 & 250 & 300\end{array}$
EMAC - Bennartz17

Cloud Droplet Number Concentration $\left[\mathrm{cm}^{-3}\right]$
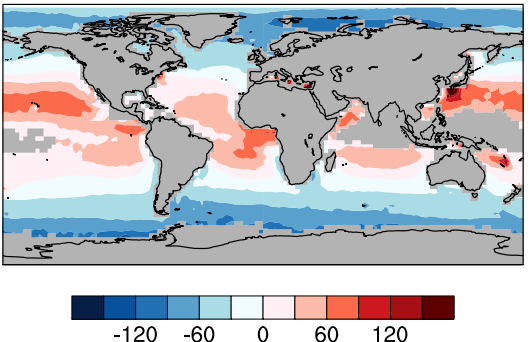

Figure S2. As in Fig. 4 in the paper, but using a different method for calculating supersaturation in liquid clouds. See Sect. 4.3 in the paper for details. 